\title{
DISPONIBILIDADE DO FÓSFORO EM ALIMENTOS DE ORIGEM VEGETAL: ATUAÇÃO NA NUTRIÇÃO DE PEIXES
}

Tânia Cristina Pontes ${ }^{1 *}$ Luana Cagol ${ }^{1}$

Fabrício Martins Dutra ${ }^{2}$ Leandro Portz ${ }^{3}$

PONTES, T. C.; CAGOL, L.; DUTRA, F. M.; PORTZ, L. Disponibilidade do fósforo em alimentos de origem vegetal: atuação na nutrição de peixes. Arq. Ciênc. Vet. Zool. UNIPAR, Umuarama, v. 18, n. 3, p. 199-205, jul./set. 2015.

RESUMO: O trabalho aborda a utilização do fósforo na nutrição de peixes e em dietas formuladas com ingredientes de origem vegetal. Nestes ingredientes, o fósforo encontra-se de forma indisponível para animais monogástricos, devido à carência da enzima fitase. A suplementação de enzimas exógenas (fitase) em ração tem por objetivo aumentar a capacidade de absorção do fósforo em dietas contendo ingredientes de origem vegetal, reduzindo a perda por excreção deste nutriente para o ambiente aquático. A enzima atua hidrolisando o fitato, tornando-o disponível para o organismo. Devido à importância do fósforo na nutrição de peixes, esta revisão apresenta alguns aspectos, sobre a importância na nutrição bem como sobre os fatores antinutricional e os benefícios causados pela inclusão da enzima em dietas balanceadas para peixes.

PALAVRAS-CHAVE: Fitato. Monogástricos. Enzima. Nutrição.

\section{PHOSPHORUS AVAILABILITY IN FOOD FROM VEGETABLE ORIGIN: PERFORMANCE IN FISH NUTRITION}

\begin{abstract}
This paper discusses the use of phosphorus in fish nutrition and diets formulated with ingredients from vegetable origin. These ingredients from, phosphorus is unavailable for monogastric animals, due to the lack of the phytase enzyme. The supplementation of exogenous enzymes (phytase) in feed is intended to increase the phosphorus absorption capacity in diets containing ingredients from vegetable origin, reducing the loss of such nutrient by excretion into the aquatic environment. The enzyme acts hydrolyzing phytate, making it available to the body. Due to the importance of phosphorus in fish nutrition, this review presents some aspects importance, and anti-nutritional factor and benefits caused by the inclusion of the enzyme in fish balanced diets.
\end{abstract}

KEY WORDS: Phytate. Monogastric. Enzyme. Nutrition.

\section{DISPONIBILIDAD DEL FÓSFORO EN ALIMENTOS DE ORIGEN VEGETAL: ACTUACIÓN EN LA NUTRICIÓN DE PECES}

RESUMEN: En este trabajo se aborda el uso de fósforo en la nutrición de peces y en dietas formuladas con ingredientes de origen vegetal. Estos ingredientes, el fósforo se encuentra de forma indisponible para animales monogástricos, debido a la falta de la enzima fitasa. La suplementación de enzimas exógenas (fitasa) en la ración tiene por objetivo aumentar la capacidad de absorción del fósforo en dietas que contienen ingredientes de origen vegetal, reduciendo la pérdida por excreción de este nutriente para el ambiente acuático. La enzima actúa hidrolizando el fitato, haciéndolo disponible para el cuerpo. Debido la importancia del fósforo en la alimentación de peces, esta revisión presenta algunos aspectos, tales como la importancia en la nutrición de peces, como el factor anti nutricional y los beneficios causados por la inclusión de la enzima en dietas balanceadas.

PALABRAS CLAVE: Fitato. Monogástricos. Enzima. Nutrición.

Introdução

A aquicultura é considerada uma prática tradicional referente à produção de diversos organismos aquáticos, dentre eles plantas aquáticas, moluscos, crustáceos e peixes (OLIVEIRA, 2009). Nas últimas cinco décadas a produção de peixes tem aumentado de forma considerável, a uma taxa média de $3,2 \%$, ultrapassando o crescimento da população mundial de $1,6 \%$ (FAO, 2014).

Com a expansão da aquicultura observa-se a busca pela otimização nas formulações de rações, crescendo o número de pesquisas sobre as exigências nutricionais (GONÇALVES et al., 2004; SIGNOR et al., 2010; BOMFIM et al., 2010), substituição de fontes alimentares (MELO et al., 2012; SILVA et al., 2014) e utilização de enzimas exógenas que atuam aumentando a biodisponibilidade de alguns nutrientes (PORTZ; BENKENDORFF; LIEBERT, 2003; SILVA et al., 2007), melhorando o desempenho produtivo, reduzindo os impactos causados por elevadas excreções de fósforo e nitrogênio no ambiente aquático (ROCHA et al., 2008; MELO et al., 2012). O fósforo como um importante mineral utilizado na nutrição de peixes atua no crescimento, mineralização ós-

DOI: https://doi.org/10.25110/arqvet.v18i3.2015.5542

${ }^{1}$ Mestranda no Programa de Pós Graduação em Aquicultura e Desenvolvimento Sustentável, pela Universidade Federal do Paraná - Setor Palotina.

${ }^{2}$ Doutorando no Programa de Pós Graduação em Zoologia, pela Universidade Federal do Paraná.

${ }^{3}$ Professor Dr. Adjunto da Universidade Federal do Paraná - Setor Palotina.

*Universidade Federal do Paraná - Setor Palotina, Bloco IV, Sala dos Técnicos, rua Pioneiro, 2153, Jardim Dallas, 85950-000. 
sea e metabolismo de lipídios (QUINTERO-PINTO et al., 2011). Entretanto, em ingredientes de origem vegetal o fósforo é encontrado na forma de fitato, indisponível para peixes devido à ausência da enzima fitase.

Portanto, a suplementação de fitase em rações para criação de peixes pode melhorar o desempenho e retenção mineral nos ossos, reduzir os níveis de inclusão de fósforo inorgânico nas rações e consequentemente minimizar os impactos provocados por esse mineral no sistema de produção e no ambiente natural (BOCK et al., 2007).

Assim, vários estudos têm sido realizados com a inclusão de fitase em rações para monogástricos (FURUYA et al., 2001; LEI; PORRES, 2003; MENDONÇA et al., 2012). Essas enzimas são produzidas a partir de um substrato dependente, em algumas circunstâncias como a idade e fisiologia da espécie animal elas podem ser produzidas em quantidades insuficientes ou não serem produzidas, dificultando a digestão dos alimentos (LIMA et al., 2011).

A elaboração de rações com nutrientes balanceados pode diminuir o excesso de matéria orgânica nos sistemas de produção e aumentar o desempenho dos peixes (CYRINO et al., 2010). Mendonça et al. (2012) em estudos com juvenis de tambaqui (Colossoma macropomum), encontraram resultados positivos para desenvolvimento produtivo com a inclusão de fitase microbiana às rações. Para Bock et al. (2007) utilizando uma ração com suplementação de fósforo e outras três com diferentes níveis de fitase (1.000, $1.500 \mathrm{e}$ $2.000 \mathrm{UFA} / \mathrm{kg}$ ) para tilápia (Oreochromis niloticus) mostrou que além da fitase diminuir a inclusão de fósforo nas rações pode também reduzir a quantidade de fósforo excretada em viveiros de piscicultura. Stech (2009) em estudo acrescentando níveis de fitase na dieta de cachara (Pseudoplatystoma reticulatum) encontrou melhora no aproveitamento das dietas.

Tendo em vista a importância do fósforo na nutrição de peixes objetivou-se com esta revisão reunir informações sobre a disponibilidade do fósforo em ingredientes de origem vegetal e a utilização de enzimas exógenas com o objetivo de aumentar a disponibilidade deste mineral nesses ingredientes.

\section{Desenvolvimento}

O fósforo é um mineral encontrado na natureza em combinações com outros elementos, como em forma de ácido fosfórico $\left(\mathrm{H}_{3} \mathrm{PO}_{4}\right)$, dihidrogenofosfato $\left(\mathrm{H}_{2} \mathrm{PO}_{4}\right)$ e em hidrogenofosfato $\left(\mathrm{HPO}_{4}^{2-}\right)$. A forma predominante no $\mathrm{pH}$ neutro é o hidrogenofosfato, enquanto que no meio ácido predominam o ácido fosfórico (QUINTERO-PINTO et al., 2011). No ambiente é encontrado nas formas inorgânica e orgânica, sendo a forma inorgânica absorvida em maior quantidade, pois as fosfatases intestinais hidrolisam a forma orgânica (QUINTERO-PINTO, 2008).

O fósforo inorgânico é representado pelos monofosfatos, bifosfatos e trifosfatos solúveis ou não no suco gástrico dos peixes, enquanto que o fósforo orgânico é representado pelos fitatos, fosfolipídios e fosfoproteínas, assim sua absorção depende do alimento utilizado na dieta (PIZZOLANTE, 2000).

Segundo Lall (2002), o fósforo é o segundo mineral de importância na estrutura óssea (37\% correspondem ao cálcio e $16 \%$ ao fósforo), por ser o componente principal do material cristalino dos ossos, conferindo rigidez, resistência e suporte. Para as melhores respostas de crescimento e mineralização óssea, os teores de fósforo disponíveis nas dietas dos peixes se apresentam entre 0,27 e 0,80\% (ANDREWS; DAVIS; CAMPBELL, 1973; KETOLA, 1975; NOSE; ARAI, 1976). Além, da importância na estrutura óssea, o fósforo ainda faz parte de diversos processos bioquímicos, como geração e transferência de energia, armazenamento de compostos fosforilados como ATP e fosfato de creatina, também faz parte do metabolismo dos fluídos corporais e aminoácidos (DATO-CAJEGAS; YAKUPITIYAGE, 1996; STRAIN; CASHMAN, 2002; MARTINI, 2006; DA SILVA; COZZOLINO, 2007).

No sangue a concentração de fósforo total é de aproximadamente $40 \mathrm{mg} / \mathrm{dL}$, como fosfolipídios das células vermelhas e lipoproteínas do plasma (QUINTERO-PINTO, 2008). Segundo Da Silva e Cozzolino (2007), aproximadamente $3,1 \mathrm{mg} / \mathrm{dL}$ se concentra na forma de fósforo inorgânico. Os rins controlam os níveis de fósforo no plasma de modo que quase todo o fósforo filtrado é reabsorvido, restando entre 0,1 a $20 \%$ que é excretado via urinária (MARTINI, 2006; DA SILVA; COZZOLINO, 2007).

Em animais monogástricos as excreções endógenas fecais representam uma rota de excreção metabólica para o controle homeostático do fósforo no plasma (BREVES; SCHRODER, 1991). A concentração de fósforo no plasma pode sofrer uma elevação temporária devido à carência de fósforo na alimentação, acarretando em aumento das perdas endógenas e urinária desse mineral (MOREIRA et al., 2004).

A ausência de fósforo na alimentação pode também prejudicar a digestibilidade de lipídios e carboidratos, afetando o crescimento (RODEHUTSCORD et al., 2000), devido a sua importante posição no metabolismo intermediário energético por meio do trifosfato de adenosina, podendo induzir a falta de apetite, escoliose, lordose, retardo no crescimento, anemia hipocrômicamicrocítica, dentre outros, podendo levar o animal ao raquitismo e morte (HELLAND et al., 2006).

Os peixes podem absorver este elemento da água, porém em pequenas quantidades, o que não supri suas necessidades, sendo que a assimilação do fósforo pelo alimento é a principal via considerada, 200 vezes superior à quantidade absorvida da água (HEPHER, 1990).

Nos ingredientes de origem animal, o fósforo encontra-se principalmente na forma inorgânica de hidroxiapatita, componente estrutural dos ossos (STEFFENS, 1987). Nos vegetais o fósforo é apresentado principalmente na forma de ácido fítico 12 (hexafosfato de inositol), este é pouco hidrolisado no intestino devido à ausência de enzimas específicas, sendo absorvido em baixas quantidades e excretado pela via fecal (STEFFENS, 1987; QUINTERO-PINTO et al., 2011). A concentração de fósforo nas plantas e sementes depende da interação de vários fatores como a espécie forrageira, o solo, o manejo das pastagens, o clima e o estado de maturidade (MCDOWELL, 1997).

Segundo Cyrino et al. (2010) a assimilação de fósforo dietético varia com a quantidade e, principalmente, a fonte dietética de fósforo utilizada (animal ou vegetal). Utilizar níveis dietéticos de fósforo ajustado às exigências nutricionais dos peixes e sua disponibilidade nos alimentos é o modo mais seguro para se evitar perdas excessivas deste elemento em ambientes aquáticos. 
Quintero-Pinto et al. (2011) relataram que o fósforo é encontrado nas rações como componente natural de moléculas biológicas e como aditivo alimentar na forma de sais, sendo que sua absorção pode ser reduzida por altas concentrações de alumínio na dieta, doses altas de carbonato de cálcio ou diminuição da temperatura da água.

O fósforo é um mineral fundamental no desenvolvimento dos peixes, sua carência na dieta pode afetar o desempenho produtivo, e o excesso ocasiona eutrofização no ambiente aquático.

Disponibilidade do Fósforo nos ingredientes de origem vegetal.

Os alimentos de origem vegetal estão sendo amplamente utilizados na formulação de rações, são produzidos em larga escala em países de clima tropical e subtropical, são alimentos proteicos e energéticos que apresentam menor custo e estão disponíveis na maior parte do ano (GONÇALVES et al., 2004). Esses alimentos apresentam fósforo em baixos níveis e pouco disponível (FURUYA et al., 2001) (Tabela 1), podendo conter cerca de 50 a $80 \%$ do fósforo na forma de fitato ou sais de ácido fítico (HARLAND; NARULA, 1999).

Tabela 1: Teor de fitato em plantas e produtos de origem vegetal.

\begin{tabular}{lccc}
\hline & $\begin{array}{c}\text { Fósforo Total } \\
(\mathbf{g} / \mathbf{k g})\end{array}$ & $\begin{array}{c}\text { Fitase } \\
\mathbf{( g / k g )}\end{array}$ & $\begin{array}{c}\text { Proporção } \\
\mathbf{( \% )}\end{array}$ \\
\hline Cereais & & & \\
Grão de trigo & 3,07 & 2,19 & 71,6 \\
Aveia & 3,60 & 2,10 & 59,0 \\
Grão de milho & 2,62 & 1,88 & 71,6 \\
Cevada & 3,21 & 1,96 & 61,0 \\
Sorgo & 3,01 & 2,18 & 72,6 \\
Centeio & 3,05 & 1,95 & 63,9 \\
Sementes Oleaginosas & & & \\
Farelo de Canola & 9,72 & 6,45 & 66,4 \\
Farelo de Algodão & 10,02 & 7,72 & 77,1 \\
Fubá & 4,24 & 2,67 & 63,0 \\
Colza & 9,60 & 6,34 & 66,0 \\
Farelo de soja & 6,49 & 3,88 & 59,9 \\
Sub-produtos & & & \\
Farelo de arroz & 17,82 & 14,17 & 79,5 \\
Farelo de trigo & 10,96 & 8,36 & 76,3 \\
Cao et al. (2007). Adaptado por NRC (1993); Selle e Ravindran (2006). &
\end{tabular}

Segundo Selle, Walker e Bryden (2003) nos cereais e sementes de oleaginosas o fósforo fítico varia em quantidade e localização, nas leguminosas, o fitato está localizado nos cotilédones, na soja encontra-se associado a corpos proteicos espalhados por toda a semente e no milho está presente no gérmen. A interação do fosfato com outros nutrientes depende da estrutura e do local de depósito de inositol fosfato, podendo este agir como um importante fator antinutricional na alimentação de monogástricos (ADEOLA; SANDS, 2003).

Miranda et al. (2000) determinaram a disponibilidade de fósforo em ingredientes de origem vegetal em rações para $O$. niloticus, em valores de coeficientes de disponibilidade do fósforo de 7,3; 35,1 e 30,7\% para o fubá de milho, farelo de soja e farelo de trigo, respectivamente. Guimarães et al. (2007) verificaram coeficientes de disponibilidade (digestibilidade aparente) do fósforo em dietas para $O$. niloticus de aproximadamente $86 \mathrm{~g}$ e encontraram valores de $26,96 \%$ para farelo de soja e de 3,51\% para farelo de algodão.

Dentre os ingredientes de origem vegetal utilizados na formulação de rações destaca-se o milho como importante fonte energética. Apesar de tal participação, este produto geralmente apresenta baixo conteúdo de fósforo total. Lovell (1978) em estudo com o bagre do canal observou que a disponibilidade aparente de fósforo em produtos cereais foi de apenas $25-28 \%$, já para o farelo de soja, encontrou disponibilidade aparente entre 50-54\%. Sigiura et al. (1998) encontraram valores de $22,0 \%$ de disponibilidade aparente de fósforo no farelo de soja para truta arco-íris (Oncorhynchus mykis) e $28,0 \%$ para o salmão (Salmo salar).

O conhecimento sobre a disponibilidade de fósforo em alguns ingredientes é de suma importância visto que se trata de um mineral essencial para o metabolismo dos peixes.

\section{Fitato}

O fitato ou hexafosfato de mio-inositol é a denominação dada à molécula de ácido fítico, forma primária de armazenamento do fósforo nos vegetais, o qual ocorre em abundância nos grãos de cereais e oleaginosas, sendo que nos vegetais sua principal função fisiológica é o armazenamento de nutrientes, principalmente o fósforo (MAENZ; CLASSEN, 1998; CONSUEGRO, 1999). A formação do fitato se dá a partir da fosforilação completa do mio-inositol que apresenta a glicose como precursora (ALMEIDA et al., 2003).

Segundo Rodrigues (2009) o ácido fítico é considerado um fator antinutricional, visto que pode se ligar a nutrientes essenciais da dieta, tornando-os parcial ou totalmente indisponíveis para sua absorção. De acordo com NRC (1994), o fósforo de origem vegetal considerado disponível para monogástricos corresponde a cerca de 30\% a 40\% da porção representada pelo fósforo não fítico.

Assim, este composto orgânico que possui um grupo ortofosfato altamente ionizado complexa com uma variedade de cátions, como o cálcio $(\mathrm{Ca})$, cobre $(\mathrm{Cu})$, zinco $(\mathrm{Zn})$, manganês $(\mathrm{Zn})$ e magnésio $(\mathrm{Mg})$ e a fração protéica do alimento, formando complexos insolúveis, diminuindo a energia metabolizável da ração devido a influência negativa na digestão dos nutrientes (KESHAVARZ ,1999; LUDKE et al., 2000).

Cousins (1999) relata que a interação com proteína se dá por ligação iônica e é dependente das condições de pH. Em meio ácido o ácido fitico possui carga negativa podendo se ligar a resíduos básicos por uma forte interação eletrostática, resultando em um complexo insolúvel. Entretanto, em pH neutro não há ligação pois as cargas do ácido fítico e da proteína são neutras.

O ácido fitico também pode interagir com importantes enzimas digestivas como a tripsina, pepsina, amilase e galactosidase, fato que resulta na diminuição da atividade dessas enzimas (SINGH; KRIKORIAN, 1982; INAGAWA; KIYOSAWA; NAGASAWA, 1987). De acordo com Kornegay e Qian (1996) o fitato prejudica a função das pepsinas 
devido às ligações iônicas entre os grupos fosfato do ácido fítico e aminoácidos como histidina, arginina e lisina em meio ácido.

A inclusão de ingredientes de origem vegetal em rações pode reduzir a disponibilidade de alguns nutrientes, como, proteínas, aminoácidos e lipídios devido à presença do fitato.

\section{Enzima Fitase}

A fitase ou mio-inositol hexa quifosfato fosfohidrolase pertence ao grupo das fosfatases de histidina que hidrolisam o fitato para mioinositol e ácido ortofosfato necessário para o processo metabólico celular (STOREBAKKEN; SHEARER; ROEM, 1998). Na natureza é encontrada nas sementes, plantas, fungos, bactérias, leveduras e microrganismos do rúmen (CAO et al., 2007). Alguns alimentos são ricos em fitase tais como farelo de trigo e de arroz, porém os ingredientes mais utilizados na fabricação de rações, contém pouca ou nenhuma atividade (SELLE, 1997).

Antes de 1990 a aplicação da fitase era realizada somente em dietas para aves e suínos para melhorar a utilização do fósforo fitico presente nos ingredientes de origem vegetal (CAIPANG; DECHAVEZ; AMAR, 2011). Em 1991 foi produzida a primeira fitase comercial Natuphos ${ }^{\circledR}$ a partir de uma estirpe de Aspergillus niger geneticamente modificada, sendo então, lançado ao mercado (KUMAR et al., 2010).

A atividade da enzima fitase é expressa em FTU (unidade de atividade de fitase), sendo 1FTU a quantidade de fósforo inorgânico liberado ( $\mu \mathrm{mol}$ ) no período de um minuto de reação numa solução de fitato de sódio na concentração de $5,1 \mathrm{mmol} \mathrm{L}^{-1} \mathrm{em} \mathrm{pH} \mathrm{5,5}$ e temperatura de $37^{\circ} \mathrm{C}$ (ENGELEN et al., 1994). Apresenta propriedade de romper ligações de fósforo orgânico ligados aos sais de ácido fítico, tornando-o disponível biologicamente nas formas de inositol e ortofosfato (LEI; PORRES, 2003). A reação catalisada pela fitase degrada o fitato a mio-inositol e fósforo inorgânico, liberando o grupo ortofosfato e, consequentemente, o grupamento amino de aminoácidos básicos e demais cátions para serem absorvidos (LUDKE, 1999).

Animais monogástricos não sintetizam nenhum tipo de fitase, fazendo com que as moléculas de ácido fítico passem através do trato gastrointestinal potencialmente indigeridas de modo que quanto maior o conteúdo de fitato nos ingredientes ou nas rações, menor a disponibilidade e absorção de fósforo (CYRINO et al., 2010). Devido à ausência de níveis adequados de fitase em animais monogástricos, o ácido fítico é excretado nas fezes, sendo necessária a adição de fosfato inorgânico nas dietas para satisfazer a exigência de fosfato e para assegurar um bom desempenho (CAIPANG; DECHAVEZ; AMAR, 2011).

O processo de extrusão das rações pode desnaturar a enzima devido a altas temperaturas fazendo com que essa perca sua atividade catalítica (KORNEGAY, 2001). Heinzl (1996) demonstrou que a fitase microbiana é estável a um amplo limite de temperatura e que a atividade máxima é próxima a $60^{\circ} \mathrm{C}$. Schwarz e Hoppe (1992) observaram que o processo de peletização em uma dieta com adição de $70 \%$ de fitase reduz a atividade da enzima de $15-25 \%$, mostrando que a fitase pode não suportar altas temperaturas. Jermutus et al. (2001) afirmam que para a maioria das fitases, o pH ótimo encontra-se em 4,5-6,0 e a temperatura em torno de 45-60 ${ }^{\circ} \mathrm{C}$.

Ramos et al. (2012) avaliaram o efeito da atividade da fitase de Aspergillus niger 11T53A9 submetida ao armazenamento de $50^{\circ} \mathrm{C}$ e durante o armazenamento sob refrigeração a $\left(3,6^{\circ} \mathrm{C}\right)$ e congelamento $\left(-16^{\circ} \mathrm{C}\right)$, a fitase permaneceu estável a $3,6^{\circ} \mathrm{C} \mathrm{e}-16^{\circ} \mathrm{C}$ por seis meses, manteve $86 \%$ de sua atividade após 24 horas na temperatura de $50^{\circ} \mathrm{C}$.

Uma alternativa que vem sendo utilizada para evitar a perda de atividade da fitase em temperaturas elevadas, principalmente no processo de extrusão é a adição da enzima em forma líquida. Geralmente, a adição é realizada mediante mistura da enzima concentrada com um estabilizante, em seguida esta é pulverizada na dieta já extrusada ou peletizada (KUMAR et al., 2011).

A adição de fitase na dieta promove o melhor aproveitamento de fósforo fítico, pois disponibiliza maiores quantidades de fósforo e outros minerais complexados, uma vez que a molécula de ácido fítico compromete a ativação do tripsinogênio e a estabilidade da tripsina (CALDWELL, 1992). Furuya et al. (2001) avaliaram o efeito da inclusão de diferentes níveis de fitase em dietas para tilápia do Nilo, sendo estes de $0,500,1.500$ e 3.000 UFA/kg de ração. Os resultados mostraram melhoras no desempenho, retenção de minerais nos ossos e digestibilidade, na ração contendo 700 UFA/kg de ração.

Assim, a suplementação de fitase na dieta pode fazer com que ocorra um melhor aproveitamento dos nutrientes de modo a permitir o melhor desempenho produtivo (MELO et al, 2012).

\section{Considerações Finais}

O fósforo é um mineral importante na nutrição animal, em ingredientes de origem vegetal, encontra-se indisponível para animais monogástricos devido à ausência da enzima fitase, sendo excretado no ambiente aquático. Devido à importância desse mineral na nutrição animal e a crescente substituição dos ingredientes de origem animal por ingredientes de origem vegetal em rações, faz-se necessário o conhecimento sobre esse mineral, sua atuação como fator antinutricional e possíveis alternativas para melhorar sua utilização.

\section{Referências}

ADEOLA, O.; SANDS, J. S. Does supplemental dietary microbial phytase improve amino acidutilization? A perspective that is does not. Journal of Animal Science, West Lafayette, v. 81, n. 2, p. 78-85, 2003.

ALMEIDA, M. V. et al. A cascata dos fosfoinositídeos. Quimica Nova, Juiz de Fora, v. 26, n. 1, p. 105-111, 2003.

ANDREWS, J. W.; DAVIS, J. M.; CAMPBELL, C. Effects of dietary calcium and phosphorus on growth, food conversion, bone ash and hematocrit levels of catfish. Journal of Nutrition, Philadelphia, v. 103, p. 766-771, 1973.

BOCK, C. L. et al. Fitase em rações para tilápia do Nilo 
na fase de crescimento. Revista Brasileira de Zootecnia, Viçosa, v. 36, n. 5, p. 1455-1461, 2007.

BOMFIM, M. A. D. et al. Níveis de lisina, com base no conceito de proteína ideal, em rações para alevinos de tilápia-do-nilo. Revista Brasileira de Zootecnia, Viçosa, v. 39, n. 1, p. 1-8, 2010.

BREVES, G.; SCHRODER, B. Comparative aspects of gastrointestinal phosphorus metabolism. Nutrition Research Reviews, Bethesd, v. 4, n. 4, p. 125-140, 1991.

CAIPANG, C. M. A.; DECHAVEZ, R. B.; AMAR, M. J. A. Potential application of microbial phytase in aquaculture. Extreme Life, Biospeology \& Astrobiology International Journal of the Bioflux Society, Philippines, v. 3, n. 1, p. 55-66, 2011.

CALDWELL, R. A. Effect of calcium and phytic acid on the activation of trypsinogen and the stability of trypsin. Journal of Agricultural and Food Chemistry, Australia, v. 40, n. 40, p. 43-46, 1992.

CAO, L. et al. Application of microbial phytase in fish feed. Enzyme and Microbial Technology, China, v. 40, n. 40, p. 497-507, 2007.

CONSUEGRO, J. P. Uso da fitase microbiana em dietas para avicultura. Industria Avícola, Jaboticabal, v. 46, n. 5, p. 27-28, 1999.

COUSINS, B. Enzimas na nutrição de aves. In: SIMPÓSIO INTERNACIONAL ACAV - Embrapa sobre Nutrição de Aves, 1.,1999, Concórdia. SC. Anais... Concórdia, 1999. p. 118-130.

CYRINO, J. E. P. et al. A piscicultura e o ambiente - o uso de alimentos ambientalmente corretos em piscicultura. Revista Brasileira de Zootecnia, Viçosa, v. 39, p. 68-87, 2010.

DA SILVA, A. Y. H.; COZZOLINO, S. M. F. Fósforo. In: COZZOLINO, S. M. F. Biodisponibilidade de nutrientes. $2^{\mathrm{a}}$ Ed. Barueri: Manol e Interesse Geral, 2007. p. 447-458.

DATO-CAJEGAS, C. R. S.; YAKUPITIYAGE, A.The need dietary mineral supplementation for Nile tilapia, Oreochromis niloticus, cultured in a semi-intensive system. Aquaculture, Amsterdam, v. 144, n. 1-3, p. 227-327, 1996.

ENGELEN, A. J. et al. Simple and rapid determination of phytase activity. Journal of Biotechnology, Bethesda, v. 77, n. 3, p. 4-76, 1994.

FAO. The State of the World Fisheries and Aquaculture. Fisheries and Aquaculture Department. Food and Agriculture Organization of the United Nations (FAO), Rome, p. 223, 2014.

FURUYA, W. M. et al. Fitase na alimentação da Tilápia do Nilo (Oreochromis niloticus). desempenho e digestibilidade.
Revista Brasileira de Zootecnia, Viçosa, v. 30, n. 3, p. 924-929, 2001.

GONÇALVES, G. S. et al. Digestibilidade aparente e suplementação de fitase em alimentos vegetais para a tilapia do Nilo. Acta Scientiarum, Maringá, v. 26, n. 3, p. 313$321,2004$.

GUIMARÃES, I. G. et al. Coeficiente de digestibilidade dos nutrientes e disponibilidade de minerais em alimentos protéicos extrusados para tilápia do Nilo (Oreochromis niloticus). In: REUNIÃO ANUAL DA SOCIEDADE BRASILEIRA DE ZOOTECNIA, 44., 2007, JaboticabalSP. Anais...Jaboticabal, 2007. p. 1-513.

HARLAND, B. F.; NARULA, G. Food phytate and its hydrolysis products. Nutrition Research, Washington, v. 15, n. 5, p. 947-961, 1999.

HEINZL, W. Technical specifications of natuphos. In: BASF TECHNICAL SYMPOSIUM, 1., 1996, Anais... Atlanta Georgia. World Congress Center, 1996. p. 39-70.

HELLAND, S. et al. Nutrición de peces comerciales en estanques. Balderas: Limusa. 406 p., 2006.

HEPHER, B. Nutrition of pond fishes. New York: Cambridge University, 1990. 407p.

INAGAWA J.; KIYOSAWA I.; NAGASAWA T. Effect of phytic acid on the hydrolysis of lactose with betagalactosidase. Agricultural and Biological Chemistry, Wakayama, v. 51, n. 11, p. 3027-3032, 1987.

JERMUTUS, L. et al. Chimeric enzymes as an alternative to directed enzyme evolution: phytase as a test case. Journal of Biotechnology, Switzerland, v. 85, n. 1, p. 15-24, 2001.

KESHAVARZ, K. Por que "es necessário emplear La fitasa em la dieta de las ponedoras? Indústria Avícola, México, v. 46, n. 10, p. 13-14, 1999.

KETOLA, H. G. Requirements of Atlantic salmon for dietary phosphorus. Transactions of the American Fisheries Society, Bethesda, v. 104, n. 3, p. 548-551, 1975.

KORNEGAY, E. T.; QIAN, H. Replacement of inorganic phosphorus by microbial phytase for young pigs fed a corn soybean meal diet. British Journal of Nutrition, Wallingford, v. 76, n. 2, p. 563-578, 1996.

KORNEGAY, E. T. Digestion of phosphorus and other nutrients: the role of phytases and factors influencing their activity. In: BEDFORD, M. R.; PARTRIDGE, G. G. Enzymes infarm animal nutrition. 10 ed. Wallingford: CABI, 2001. p.237-271.

KUMAR, V. et al. Dietary roles of phytate and phytase in human nutrition: A review. Food Chemistry, Germany, v. 120, n. 4-15, p. 945-959, 2010. 
KUMAR, V. et al. Phytate and phytase in fish nutrition. Journal of Animal Physiology and Animal Nutrition, Germany, v. 96, p. 335-364, 2011.

LALL, S. P. The Minerals. In: HALVER, J. E.; HARDY, R. W. Fish Nutrition. 3. Ed. Elsevier Science (USA), 2002. p.259-308.

LEI, X. G.; PORRES, J. M. Phytase enzymology, applications, and biotechnology. Biotechnology Letters, Amsterdam, v. 25, n. 21, p. 1787-1794, 2003.

LIMA, M. R. et al. Alimentos funcionais. Nutritime, Areia, v. 8, n. 5, p. 1546-1557, 2011.

LOVELL, T. Dietary phosphorus requirements of channel catfish (Ictalurus punctatus).American Fisheries Society, Alabama, v. 107, n. 4, p.617-621, 1978.

LUDKE, M. C. M. M. O efeito da fitase sobre a disponibilidade do nitrogênio, fósforo e cálcio em dietas para suínos. 1999. 233 f. Doutorado (Doutorado em Zootecnia)- Universidade Federal do Rio Grande do Sul, Porto Alegre, 27 de jan, 1999.

LUDKE, M. C. M. M. et al.Efeito da fitase em dietas com ou sem fosfato inorgânico para suínos em crescimento.

Revista Brasileira de Zootecnia, Viçosa, v. 29, n. 2, p. 485-494, 2000.

MAENZ, D. D.; CLASSEN, H. L. Phytase activity in the small intestinal brush border membrane of the chicken.

Poultry Science, Saskatoon, v. 77, n. 19, p.557-563, 1998.

MARTINI, L. A. Cálcio e fósforo. Rio de Janeiro: Guanabara Koogan, 2006, 236 p.

MCDOWELL, R. L. Minerals for grazing ruminants in tropical regions. Flórida, 3 ed. 1997, 90 p.

MELO, K. D. M. et al. Adição de fitase em rações para tilápia-do-Nilo. Revista Portuguesa de Ciências Veterinárias, Lisboa, v. 107, n. 3, p. 581-582, 2012.

MENDONÇA, P. P. et al. Efeito da suplementação de fitase na alimentação de juvenis de tambaqui (Colossoma macropomum). Archivos de Zootecnia, Córdova, v.61, n. 235, p.437-448, 2012.

MIRANDA, E. C.et al. Disponibilidade aparente de fósforo em ingredientes pela tilápia do Nilo (Oreochromis niloticus). Acta ScientiarumAnimal Sciences, Maringá, v. 22, n. 3, p. 669-675, 2000.

MOREIRA, J. A. et al. Fluxo biológico do fósforo no metabolismo de suínos alimentados com dietas contendo fitase. Revista Brasileira de Zootecnia, Viçosa, v. 33, n. 6 , p. 2066-2075, 2004.

NOSE, T.; ARAI, S. Recent advances on studies on mineral nutrition of fish in Japan. In: PILLAY, P. V. L.; DILL, W. A.
Advances in aquaculture. London: Fishing News, 1976. p. 584-590.

NRC. National Research Council. Nutrient requirements of fish. Washington, 1993, 114 p.

NRC. National Research Council. Nutrient requirements of poultry. Washington, 1994.176p.

OLIVEIRA, R. C. O. Panorama da aqüicultura no brasil: A prática com foco na sustentabilidade. Revista Intertox de Toxicologia, Risco Ambiental e Sociedade, São Paulo v. 2, n. 1, p. 1-78, 2009.

PIZZOLANTE, C. C. Estabilidade da fitase e sua utilização na alimentação de frangos de corte. 2000. 117 f. Tese (Doutorado em Zootecnia)-Universidade Federal de Lavras, Lavras, 2000.

PORTZ, L., BENKENDORFF, K., LIEBERT, F. Growth and mineral absorption of Nile tilapia Oreochromis niloticus fed a plant based diet supplemented with microbial phytase. AquacultureSociety, Germany, v. 1, n. 2, p. 1-592, 2003.

QUINTERO-PINTO, L. G. et al. Exigências e disponibilidade de fontes de fósforo para tilápias. Veterinária e Zootecnia, Botucatu, v. 5, n. 2, p. 30-43, 2011.

QUINTERO-PINTO, L. G. Exigências dietarias e disponibilidade de fontes de fósforo para tilápia do Nilo (Oreochromis niloticus). 2008. 90 f. Tese (Doutorado em zootecnia)-Universidade Estadual Paulista, Botucatu, 2008.

RAMOS, G. D. M. et al. Estabilidade da fitase de Aspergillus niger 11T53A9 ao armazenamento e sua aplicação na hidrólise do ácido fítico na farinha de sorgo. Revista Brasileira de Agrociência, Pelotas, v. 18 n. 2-4, p. 95-106, 2012.

ROCHA, C. B. et al. Suplementação da enzima fitase e o desempenho e retenção mineral em juvenis de jundiá (Rhamdia quelen). Boletim Instituto de Pesca, São Paulo, v. 34, n.1, p. 151- 157, 2008.

RODEHUTSCORD, M. et al. Availability and utilisation of free lysine in rainbow trout (Oncorhynchis mykiss). Comparison of L-lysine $\mathrm{HCl}$ and L-lysine sulphate. Aquaculture, Germany, v. 187, n. 2, p. 177-183, 2000.

RODRIGUES, V. V. Redução de nutrientes em ração com fitase para suínos em crescimento. 2009. 52 f. Dissertação (Mestrado) - Universidade Federal de Lavras, Lavras, 2009.

SCHWARZ, G.; HOPPE, P. P. Phytase enzyme to curb pollution from pigs and poultry. Feed Magazine, New York, v. 13, n.6, p. 22-26, 1992.

SELLE, P. H. The potential of microbial phytase the sustainable production of pigs and poultry. In: Short Course on feed Technology. Korea: Korean Society of 
Animal. Nutrition and Feedstuffs, 1997. p. 1-39.

SELLE, P.H.; WALKER, A.R.; BRYDEN, W.L. Total and phytate-phosphorus contents and phytase activity of Australian-sourced feed ingredients for pigs and poultry. Australian Journal of Experimental Agriculture, Australia, v. 43, n. 5, p. 475-479, 2003.

SELLE, P. H.; RAVINDRAN, V. Microbial phytase in poultry nutrition.Animal Feed Science and Technology, Palmerston North, v. 135, n. 2, p. 1-41, 2006.

SIGNOR, A. A. et al. Proteína e energia na alimentação de pacus criados em tanques-rede. Revista Brasileira de Zootecnia, Viçosa,v. 39, n. 11, p. 2336-2341, 2010.

SILVA, J. A. M. et al. Digestibilidade aparente dos nutrientes e energia de ração suplementada com enzimas digestivas exógenas para juvenis de tambaqui (Colossoma macropomum Cuvier, 1818). Acta Amazonica, Manaus, v. 37, n. 1, p. 157-164, 2007.

SILVA, T. R. M. et al. Substituição parcial do milho pelo resíduo de macarrão em dietas para tilápia-do-nilo. Boletim Instituto de Pesca, São Paulo, v. 40, n. 4, p. 669-676, 2014.

SINGH,M.; KRIKORIAN, A. D. Inhibition of trypsin activity in vitro by phytase. Journal of Agricultural and Food Chemistry, v. 30, n. 4, p. 799-800, 1982.

STECH, M. R. Enzimas exógenas na alimentação de cachara (Pseudoplatystoma reticulatum). 2009. 129 f. Tese (Doutorado)-Universidade Estadual Paulista, Jaboticabal, 2009.

STOREBAKKEN, T.; SHEARER, K. D.; ROEM, A. J. Availability of protein, phosphorus and other elements in fish meal, soy-protein concentrate and phytase-treated soyprotein-concentrate-based diets to Atlantic salmon, Salmo salar. Aquaculture, Amsterdam, v. 161, n. 4, p. 365-379, 1998.

STRAIN, J. J.; CASHMAN, K. D. Minerais e oligoelementos. Rio de Janeiro: Guanabara, 2002, 205 p. 